\title{
Gênero: breve história de um conceito
}

\author{
Maria Luiza Heilborn \\ Carla Rodrigues ${ }^{2}$
}

Resumo: O objetivo desse artigo é discutir a importância da construção do conceito de gênero em diversos campos de estudos, seguindo um percurso que pretende argumentar em favor do conceito de gênero como importante operador para a crítica de situações sociais específicas nas quais as mulheres ainda são subjugadas, tomando como exemplos o mercado de trabalho e o ambiente da família e sustentando sua importância no âmbito da educação.

Palavras-chaves: gênero, hierarquia de gênero, heteronormatividade.

\section{Gender: brief history of a concept}

\begin{abstract}
The aim of this article is to discuss the importance of the concept of gender in several fields of study, following a path that seeks to argue in favor of the concept of gender as an important operator for the critique of specific social situations in which women are still subjugated, taking as examples the labor market and the family environment and sustaining its importance in the scope of education.
\end{abstract}

Key-words: gender, gender hierarchy, heteronormativity.

1 Historiadora, doutora em Antropologia pelo Museu Nacional (UFRJ), professora e pesquisadora no Instituto de Medicina Social da Uerj.

2 Doutora em Filosofia pela PUC-Rio, professora do Programa de Pós-Graduação de Filosofia (PPGF/IFCS) e bolsista de produtividade da Faperj. E-mail carla.ifcs@gmail.com 
Conceitos têm história, são formados e configurados a partir de ideologias, exigências políticas, debates e reflexões que circulam entre pensadores; são também objeto de disputas e discussões que não podem pretender esgotá-los, encerrá-los ou estabilizá-los em uma definição única, supostamente neutra e definitiva. A história do conceito de gênero, da qual nos ocuparemos neste artigo, exemplifica, desde a segunda metade do século XX, essas idas e vindas, em campos como a Antropologia, as Ciências Sociais e a Filosofia. Esta história ganha, no início do século XXI, questionamentos aos quais nos interessa chegar a fim de fazer pensar até que ponto o conceito de gênero - a partir do qual se tem discutido a assimetria de gênero na sociedade -, pode ser repensado em nome do debate sobre a heteronormatividade. Numa certa perspectiva, o conceito de gênero seria insuficiente para pensar e, mais ainda, politizar a heteronormatividade. Neste artigo, vamos seguir um percurso que pretende argumentar em favor do conceito de gênero como importante operador para a crítica de situações sociais específicas nas quais as mulheres ainda são subjugadas, tomando como exemplos o mercado de trabalho, o ambiente da família e a sua necessária discussão no ambiente escolar.

\section{Gênero e diferença sexual nas Ciências Sociais}

$\mathrm{Na}$ história das teorias sociais sobre diferenças sexuais, a distinção sexo/gênero abriu a possibilidade de interrogar a ideia de diferença sexual como princípio universal de diferença e de classificação (DURKHEIM e MAUSS, 1971 [1903]). A antropóloga Françoise Héritier será uma das exceções na escola sociológica francesa, ao defender um prisma materialista (BONTE, 2009: 97) sobre a diferença sexual no que concerne à especialização dos corpos humanos referente à reprodução sexuada e seus diversos desdobramentos, ressalvando-se que o termo gênero não é incorporado em sua obra (HÉRITIER, 1996). A partir da dessemelhança sexo/gênero, delineiam-se os argumentos para pensar a diferença ${ }^{3}$ sexual como produto da cultura e não como substrato natural ou essência que informaria a modelação dos chamados papéis sexuais. Nesta abordagem, indivíduos nascidos e classificados como homens e mulheres seriam socializados para agir, pensar e sentir segundo roteiros culturalmente construídos em posições vinculadas ao sexo anátomo-biológico. São perspectivas que trabalham a partir da construção cultural dos papéis de gênero e tendem a conceber as relações entre os sexos a partir de pressupostos de costume e estabilidade social. Em geral, tendem também a descartar a possibilidade de mudança nesse arranjo social.

Aqui, argumenta-se que a noção de sexo, ou da natureza biológica de homens e mulheres, é uma construção social (LAQUEUR, 2001, MOORE, 1991; OUDSHOORN, 1994), e o corpo sexuado como entidade não pode ser considerado um dado universal. A década de 1970 foi marcada pela progressiva

3 A antropóloga Henrietta Moore (1991) designa que o que aproxima o feminismo da Antropologia é o pensamento da diferença, apesar de em alguns momentos o feminismo haver pleiteado a semelhança entre todas as mulheres. 
incorporação do conceito de gênero (HEILBORN e SORJ, 1999) nas Ciências Sociais e na História. A distinção sexo/gênero foi se constituindo como ferramenta conceitual e política e representou um argumento decisivo nas lutas em torno dos direitos das mulheres. Nesse processo de diferenciação, o primeiro termo - sexo - remete à natureza e, de maneira mais específica, à biologia, e o segundo termo - gênero - se refere às construções culturais das características consideradas femininas e masculinas. Tais construções são percebidas como aspectos que mantêm relação com a biologia, mas dela não derivam e variam em diferentes contextos. Ao iluminar o caráter arbitrário das noções de masculinidade e feminilidade, a distinção entre sexo e gênero permitiu que pesquisadoras e militantes feministas salientassem a natureza eminentemente social da subordinação das mulheres, e apontassem, portanto, para sua possível alteração (FRANCHETTO, CAVALCANTI e HEILBORN, 1981; MATHIEU, 1991).

\section{Sexo e gênero como sistema na Antropologia}

O "sistema de sexo e gênero", inaugurado por Gayle Rubin (1975), propõe que a assimetria entre homens e mulheres, presente em múltiplas sociedades, deveria ser debitada às formas de organização social do sexo e da reprodução. Interpelando Lévi-Strauss (1976) na teoria sobre a circulação de mulheres, Rubin indica que a desigualdade de distribuição de poder está na raiz da apropriação pelos homens da capacidade reprodutiva do sexo feminino. Essas ideias são centrais no desenvolvimento da Antropologia dedicada ao gênero nas décadas de 1970 e 1980 (HARRIS e YOUNG, 1979; RITER, 1975). No marco de abordagens que consideram a subordinação feminina um aspecto universal da organização social, o conceito de gênero foi amplamente utilizado como instrumento de crítica à construção social das diferenças entre homens e mulheres, de forma a compreender as maneiras como essas convenções se relacionavam com as práticas sociais, situando as mulheres em posições de desigualdade. Algumas antropólogas definiram gênero como uma forma de desigualdade social (ORTNER e WHITEHEAD, 1981; COLLIER e YANAGISAKO, 1987) e consideraram o estudo do gênero como o estudo de relações assimétricas de poder e oportunidades.

$\mathrm{Na}$ trajetória do conceito de gênero como ferramenta de interpelação da naturalização das relações sociais e da diferença sexual, desde que foi publicado, em 1986, no volume 5 da edição 91 da American Historical Review , "Gênero - uma categoria útil de análise histórica", da historiadora e teórica feminista Joan Scott, se tornou a grande referência no Brasil para o uso do termo no debate sobre hierarquia ou assimetria de gênero. Sabemos que o texto de Scott muito contribuiu para que pesquisadores da área de ciências humanas reconhecessem o valor das pesquisas sobre as relações sociais estabelecidas com base nas diferenças percebidas entre homens e mulheres. O conceito de gênero passou a ser usado para evidenciar que o sexo anatômico não é o único elemento definidor das condutas da espécie humana. As culturas criam padrões associados aos corpos que se distinguem por seu aparato genital e pela capacidade de gerar outros seres (isto é, pela reprodução humana). Diferença sexual, 
sexualidade (heterossexual) e gênero passam a ser dimensões que se cruzam, mas uma não decorre da outra.

"O gênero é uma estratégia pela qual as feministas começaram a encontrar uma voz teórica própria, além de aliados científicos e políticos. É nesse espaço que gênero é uma categoria útil de análise" (SCOTT, 1990, p. 14). A autora argumenta a favor do uso do gênero como categoria de análise ao defender o conceito como forma de compreender os diversos modos de interação social e humana. Scott sustenta o gênero como aquilo que nos permite interrogar como a diferença sexual funciona nas relações sociais. Na medida em que gênero se integra na metodologia das Ciências Sociais, conforme tal categoria se torna aquela a que se recorre para rejeitar explicações biológicas para as relações sociais, e, sobretudo, quando gênero aparece como uma classificação social que se impõe sobre um corpo sexuado, a categoria nos oferece novas perspectivas sobre as relações de poder e nos permite pensar igualdade política e social com o objetivo de incluir, além da dimensão de gênero, as questões de classe e raça que até ali subjaziam em análises cujo ponto de partida era a neutralidade do humano. Poderíamos acrescentar que outras dimensões, como a homossexualidade, também aparecem como problema teórico no âmbito de um novo registro epistemológico que incorpora o gênero como categoria estratégica de análise.

\section{A crítica ao destino biológico das mulheres}

Escrito em 1949, O segundo sexo (1949 [2009]) marcaria o início da reflexão sobre a subalternidade feminina, que anos depois foi encampado pelos que se passou a chamar de "estudos de gênero", caracterizado pela defesa da ideia de que a biologia não pode ser o fator determinante na diferenciação entre homens e mulheres. " $\mathrm{Na}$ humanidade, as 'possibilidades' individuais dependem da situação econômica e social", escreve Beauvoir, que apresenta, a partir do que entende que seja uma construção social, uma visão de que a hierarquia entre masculino e feminino está fundamentada na cultura, começando na experiência familiar, passando pela educação nas escolas, pela tradição e pela religião.

Beauvoir parte da premissa de que a hierarquia entre masculino/feminino está dada pela mesma oposição cultura/natureza, estando o masculino e a cultura na parte privilegiada dessa hierarquia, e o feminino e a natureza na parte inferior. A pensadora francesa se opõe diretamente ao pensamento de Rousseau, cujo projeto era educar as mulheres em direção a uma passividade tida como "natural" ou biológica. Beauvoir questiona essa natureza quando diz que esse destino lhe é imposto por seus educadores e pela sociedade (BEAUVOIR, 2009).

A partir da publicação de O segundo sexo, esse destino biológico das mulheres passa a ser questionado e forma-se a ideia de que o "sexo" é biológico e o gênero é socialmente construído. Embora não seja a iniciadora do movimento feminista - em vários momentos históricos anteriores, ocorreram iniciativas políticas de mulheres que buscavam alterar sua posição subalterna na sociedade, como a luta das sufragistas -, o fato é que a obra de Beauvoir é um marco na produção teórica feminista do século 
XX, que influenciou as Ciências Sociais - o já mencionado trabalho de Rubin é tributário das reflexões de Beauvoir - e abriu pelo menos dois debates importantes. O primeiro, sobre o lugar da mulher como o outro do homem, questão que se desdobrará, por exemplo, a partir da filosofia de Emanuel Lévinas.

O segundo, com suas proposições sobre a mulher como categoria universal, que vieram a ser interrogadas pela teoria feminista e pelo pensamento da filósofa norte-americana Judith Butler. Percebida como uma importante continuadora da obra de Foucault ${ }^{4}$, Butler segue a trilha do pensador francês para desconstruir o corpo "natural” e afirmá-lo tão cultural quanto o gênero (BUTLER, 1987). Se em Scott a pergunta era "como o gênero funciona nas relações sociais", em Butler a pergunta se desloca para "como o gênero funciona na definição ontológica de sujeito”. Mais do que um problema epistemológico, uma das questões que esse deslocamento põe em xeque é o desafio de pensar as relações sociais de gênero não mais a partir da distinção sexo/gênero, mas a partir de um trinômio sexo/gênero/desejo (BUTLER, 2003), no qual a heterossexualidade compulsória possa ser interrogada como heteronormatividade.

Rubin (1984), cuja influência sobre o trabalho de Butler é notória, percebe que a elaboração acerca da sexualidade frente ao gênero provida pelo sistema sexo/gênero, por ela proposto em 1975, não dá conta da especificidade da sexualidade. Segundo a autora, há uma hierarquia de valores sexuais, na qual a sexualidade considerada "boa", "normal" e "natural" seria idealmente heterossexual, marital, monogâmica, reprodutiva e não comercial. Deve ser concebida por um casal, relacional, ocorrer com pessoas da mesma geração e dentro de casa. Não deve envolver pornografia, objetos de fetiche, brinquedos sexuais ou papéis que não o masculino e o feminino. Qualquer sexo que viole este modelo é considerado "mau", "não natural" e "anormal".

Partindo das contribuições de Rubin e de uma crítica à influência do existencialismo em Beauvoir, Butler estabelece um debate sobre a distinção sexo/gênero, para ela ainda inscrita na tradição cartesiana que orientou o pensamento ocidental sobre o sujeito. Butler vê na divisão sexo/gênero a ideia de que pensar o sexo como natural e o gênero como socialmente construído mantém um modelo binário. Tratase, então, de discutir como e se a noção de gênero decorre do sexo, decorrência na qual ela aponta uma forma de afirmação de uma "unidade metafísica". Para Butler, aceitar o sexo como um dado natural e o gênero como um dado construído, determinado culturalmente, seria aceitar também que o gênero expressaria uma essência do sujeito. Podemos pensar que seu gesto político histórico - a partir do qual também se impõe a necessidade de pensar sobre a utilidade do uso da categoria de gênero como análise

\footnotetext{
4 Quando Foucault publica História da sexualidade - a vontade de saber (1973), seu projeto é demonstrar como a emergência de uma nova episteme gerada no século XVIII dá existência a uma intricada teia de relações em que se entrelaçam saber-poder. Opondo-se à hipótese de que todo o poder emana do Estado, o pensador francês focaliza os micropoderes que constituem a nova ordem, a do poder disciplinar. Foucault escreve na contracorrente do pensamento da época, opondo-se de maneira entricheirada aos arautos de uma nova era de liberdade sexual após séculos de repressão. O conjunto de análises sobre a produção de conhecimento sobre o louco, o criminoso, a sexualidade, o corpo doente coroa na enunciação da disciplina como o mecanismo central de teias de controle social. Foucault enfoca o contraste entre o poder soberano - que coíbe, coage e reprime - ao do novo poder, dotado de eficácia produtiva - que resulta em individualização por meio de dispositivos diversos, como o isolamento em celas asilares ou prisionais, técnicas de exames, registros, vigilância panóptica e classificação minuciosa dos 'desvios'. O caráter positivo dessa modalidade de poder é a produção de realidade e sentimentos até então inexistentes, como o próprio sentimento de si.
} 
- é afirmar que não há a verdade do gênero (BUTLER, 2003, p.195). Ao indicar que não há essência ou identidade nas características corporais, a autora propõe três dimensões contingentes da corporeidade, escapando, assim, do binarismo de gênero: sexo anatômico, aquele dado pela biologia; identidade de gênero, entendida como uma construção social; e performance de gênero, sendo o elemento do performativo aquilo que perturba a associação sexo/gênero e explicita sua arbitrariedade.

A partir do questionamento da verdade do gênero, Butler sugere que os debates teóricos que dizem respeito a estabelecer uma prioridade entre os termos gênero, diferença sexual e sexualidade estão atravessados por um outro problema: a permanente dificuldade de determinar onde começa e termina o biológico, o psíquico, o discursivo e o social. Butler entende que a diferença sexual é o lugar no qual se coloca a questão da relação entre o biológico e o cultural, quando afirma que "gênero é a parte da diferença sexual que aparece como social” (BUTLER, 2004, p. 185).

\section{Hierarquia de gênero e mercado de trabalho}

A hierarquia social baseada na materialidade dos corpos se expressa, por exemplo, na divisão de gênero no trabalho, na qual mulheres ganham menos do que homens, são naturalmente direcionadas a atividades tidas como essencialmente femininas - organização, arrumação, cuidado - mesmo entre dois profissionais em cargos equivalentes. Em outras palavras, entre um homem e uma mulher, ambos gerentes, além da desigualdade salarial, haverá também uma hierarquia simbólica organizada a partir de uma diferença sexual. Em todos os países capitalistas desenvolvidos, a maioria dos empregos de tempo parcial é de mulheres. Nos países em desenvolvimento, elas também são maioria nas atividades informais e, em todos os países do mundo, as mulheres ocupam postos de trabalho mais precários ou de vínculo mais frágil do que os homens (HIRATA, 2006).

Ainda que as mulheres estejam amplamente representadas - elas correspondem a cerca de 45\% da população economicamente ativa -, a desigualdade de renda e de acesso aos postos mais altos na hierarquia, seja na administração pública, seja na iniciativa privada, são questões a ser enfrentadas ${ }^{5}$ para o benefício de todas as mulheres que, atuando no mercado de trabalho, buscam oportunidades de ascensão social e superação das desigualdades de renda.

Conhecemos bem as consequências da discriminação contra as mulheres nesse campo: menor reconhecimento profissional, menos acesso aos postos de poder, menos oportunidades de carreira,

\footnotetext{
5 No Brasil, diferentes pesquisas apontam para o mesmo cenário: embora elas tenham maior escolaridade, os rendimentos das mulheres são menores do que os dos homens, mesmo quando elas ocupam cargos de maior prestígio. Apesar de a participação relativa das mulheres no contingente de formados ter aumentado em praticamente todos os cursos universitários, a diferença salarial em relação aos homens caiu pouco. Indicadores do IBGE (PNAD, 2007) mostram que as mulheres são maioria nas faixas salariais mais baixas e minoria nas mais altas, e essa tendência se mantém inalterada há pelo menos duas décadas. $\mathrm{Na}$ administração federal, pesquisa mostra que, embora ocupem $43 \%$ dos cargos federais, as mulheres são minoria nas vagas superiores da hierarquia, em que $80 \%$ dos postos são ocupados por homens. As mulheres no topo da carreira pública são minoria nas três faixas salariais mais altas: 36\% ganham DAS-4, 21\% recebem DAS-5 e somente 19\% têm a remuneração máxima, DAS-6 (FONTELE-MOURÃO, Tânia. Mulheres no topo de carreira: flexibilidade e persistência. Brasília: SPM, 2006).
} 
salários mais baixos, mais mulheres subempregadas ou em trabalhos precários. Um dos argumentos desta assimetria ainda é a natureza dos corpos, exemplificado no debate do famoso caso Sears, empresa que, no final da década de 1970, foi acusada de discriminação sexual contra mulheres na contratação de mão de obra para postos competitivos e de salários mais altos. Nos EUA, como aponta Vicki Schultz (1992), os tribunais têm sido importante fórum de debate sobre a questão, e empregadores recorrem sistematicamente ao argumento de que as mulheres não estão interessadas em ocupar cargos de chefia ou mais bem remunerados, o que seria característica comum da identidade feminina.

Em 1979, a Comissão de Oportunidades Iguais de Emprego (EEOC, sigla em inglês) moveu um processo contra a Sears, maior empresa de varejo dos EUA e maior empregadora de mulheres no âmbito privado, por discriminação sexual na contratação de mão de obra para áreas mais bem remuneradas, como a de vendas por comissão, em que a maioria dos funcionários eram homens. Dois lados se enfrentaram: a defesa da Sears procurou demonstrar que não havia interesses iguais entre homens e mulheres em relação aos postos de trabalho, por isso, havia maior presença dos homens nos postos mais altos; a acusação quis mostrar que os empregadores não ofereceriam oportunidades, o que configuraria discriminação. Se houvesse oportunidade, as mulheres assumiriam funções que tradicionalmente são tidos como masculinas.

Duas historiadoras feministas foram peças-chave no tribunal: Alice Kessler-Harris, pela acusação, e Rosalind Rosenberg, pela defesa. Primeiramente, a defesa quis demonstrar que não havia interesses iguais entre homens e mulheres em relação aos postos de trabalho. A acusação replicou o argumento, levando ao tribunal exemplos de que, quando as oportunidades são oferecidas, as mulheres assumem, sim, ocupações que não são tomadas como "femininas". O que, no entanto, fez do caso Sears um episódio singular na discussão sobre a presença da mulher no mercado de trabalho foi o fato de que, na tréplica contra a acusação, a defesa da empresa se valeu de argumentos da testemunha de acusação, a historiadora Alice Kessler-Harris.

Anos antes do julgamento, ela havia publicado um artigo sobre as diferenças na maneira como homens e mulheres encaram o mercado de trabalho, mostrando que mulheres são mais domesticamente orientadas e menos individualistas do que os homens, o que terminava por concordar com a argumentação da defesa da Sears, feita por Rosenberg. A autora tratara como "natural” a diferença de aspirações masculinas e femininas nos postos de trabalho da empresa, recuperando o argumento do determinismo biológico que justificaria as distinções nos interesses de homens e mulheres. Para Rosenberg, mesmo diante de oportunidades iguais, as mulheres fariam escolhas baseadas em valores femininos, diferentes do modelo tradicional masculino. Segundo ela, essas escolhas mantêm as mulheres em postos menos competitivos ou menos orientados a ganhos econômicos. A estratégia da defesa venceu o debate e convenceu o juiz de que a distribuição dos postos de trabalho na Sears poderia ser explicada pelas diferenças existentes entre homens e mulheres, e não como resultado de qualquer política discriminatória. "A pressuposição de interesses iguais [entre homens e mulheres] é infundada e solapa 
fatalmente toda a sua análise estatística” (Norderberg, apud PIERUCCI, 1999, p. 42).

O caso Sears foi emblemático porque, pela primeira vez, a discriminação sexual no trabalho foi tratada como uma escolha das mulheres, argumento usado posteriormente pelas empresas em 54 outros processos. Em 46\% deles o Judiciário aceitou a defesa das empresas, baseada na ideia de que a diferença da posição feminina nos postos de trabalho era resultado da falta de interesse das mulheres em cargos mais altos da hierarquia, justificativa dos empregadores para a discriminação (SCHULTZ, 1992).

Schultz indica que se abriu um campo de discussão sobre a articulação entre lei e identidade, a partir do momento em que a justiça aceitou os argumentos dos empregadores e passou a interpretar a segregação sexual no mercado de trabalho como expressão da falta de interesse das mulheres em postos mais bem remunerados. A autora aponta para o problema de a justiça ser chamada a caracterizar as aspirações e a identidade das mulheres como um grupo (SCHULTZ, 1992), estabelecendo a premissa de que as mulheres, como categoria identitária, não aspiram a empregos melhores, o que permitiu aos empregadores determinar preferências de gênero que justificam a segregação sexual no mundo do trabalho. Ela se apoia em inúmeros estudos que mostram como os empregadores construíram a ideia de que há empregos tradicionais femininos para exigir das mulheres comportamentos que são considerados preexistentes como atributos da feminilidade ${ }^{6}$.

A autora questiona a afirmação de que as mulheres querem postos inferiores "por sua própria escolha", e não como parte de um processo cultural de predeterminação do que são os atributos das mulheres. Schultz critica ainda o fato de os tribunais terem assumido como premissa que o interesse das mulheres no trabalho é configurado exclusivamente por sua vida privada, independentemente das exigências do mundo do trabalho. O problema, ainda seguindo Schultz, é que, a partir do episódio Sears, o Judiciário estabeleceu um determinado viés para deliberar sobre casos de segregação sexual nas empresas e os juízes adotaram a tese de que as diferenças de oportunidade estavam ligadas à falta de interesse das mulheres nos postos mais altos da carreira, reforçando os argumentos essencialistas sob os quais se fundamenta a hierarquia de gênero no mercado de trabalho.

\section{Gênero e esfera doméstica}

O impacto dos estudos sobre gênero em algumas áreas tradicionais, como a sociologia do trabalho, propiciou o interesse em relacionar a experiência desse âmbito com outras esferas, que uma definição ortodoxa do trabalho não permitia enxergar como produtora de valor. Assim, se advogava a ideia de que as regras do mercado se aplicariam à produção, ao passo que o trabalho doméstico seria, por assim dizer, "um dote natural que as mulheres aportariam ao casamento em troca do provimento realizado pelos maridos" (SORJ, 2000, p. 165).

$6 \mathrm{COHN}, \mathrm{S}$. The process of occupational sex-typing: the feminilization of clerical labor in Great Britain. 1985; KANTER, Rosabeth Moss. Men and Women of the corporation. 1977; e WILLIANS, C. Gender differences at work: women and men in nontraditional occupations. 1989. 
Outra dimensão do trabalho doméstico encapsulada nos afazeres diários é o que hoje se denomina como care, que designa toda a sorte de cuidados para com a prole ainda não adulta, o parceiro e pessoas que, por envelhecimento, perderam a capacidade de autonomia e demandam de figuras, na sua grande maioria, femininas, quando o Estado é incapaz de fornecer serviços para atendimento às necessidades de seres dependentes.

Desse modo, a discussão sobre gênero adentrou a redoma sacralizada da família, na qual a troca de bens e prestação de serviços é naturalizada como logicamente decorrente da "natureza feminina", na qualidade de dádiva na acepção antropológica do termo. Sorj e muitas outras sociólogas (cf. HIRATA e GUIMARÃES, 2012) demonstraram como a esfera familiar não pode mais ser vista como um sistema de posições fixas, livre dos constrangimentos externos gerados pelo mercado de trabalho. A filósofa e cientista política Joan Tronto (1996) afirma que o cuidado é o fundamento da vida social. Podemos dizer que sua perspectiva se aproxima daquela usual na Antropologia que define a reciprocidade (MAUSS, 2003; CAILLÉ, 1998) como cimento social não redutível à mercantilização.

Uma personagem importante deste debate é a psicóloga Carol Gilligan, pioneira na reflexão sobre a relação entre cuidado e gênero. Ela identificou que nos estudos sobre teoria da moral prevalecia um viés masculino (GILLIGAN, 1979), e propõe a ética do cuidado - feminina - como uma alternativa legítima àquilo que era definido como o padrão do julgamento moral na perspectiva de justiça compatível com a teoria liberal, na qual os valores individuais prevalecem sobre os da comunidade. Vários autores, então, argumentavam que as mulheres apresentariam um desenvolvimento moral menos universalista, aquém, comparativamente, aos homens na compreensão de justiça e equidade. Mais adiante, Gilligan (1982) recusou de maneira vigorosa a interpretação de leituras sobre seu trabalho que vinculavam estreitamente a ética do cuidado ao gênero, apesar de haver sempre sustentado que mulheres tenderiam a revelar uma ética relacional.

A relacionalidade atribuída ao feminino tem sido objeto de longa discussão nos estudos sobre família no âmbito da antropologia brasileira (ARAGÃO, 1983, DUARTE, 1986, FONSECA, 1991, SARTI, 1989, CABRAL e HEILBORN, 2014). Não se trata de postular uma natureza feminina, mas, antes, de salientar que por força de intensa socialização e formas de estruturação da família e da conjugalidade, às mulheres coloca-se o núcleo estruturador de vínculos familiares e do cuidado para com os membros do grupo familiar, tendo importante impacto, por exemplo, na prestação dos cuidados de saúde, que confirma a hierarquia de gênero na medida em que o cuidado não tem estatuto de trabalho no mercado de trocas e valores. 


\section{Conclusões finais: sobre o conceito de gênero na escola}

Pretendemos neste breve percurso histórico apontar o desenvolvimento do conceito de gênero, seus usos em campos como as Ciências Sociais, a Antropologia e a Filosofia, salientando que o gênero, para além de uma dimensão da pessoa, aspecto crucial na alta modernidade, constitui-se em um eixo de classificação que organiza as relações sociais. Com os exemplos sobre a divisão sexual do trabalho, seja no mercado, seja nos cuidados de saúde no âmbito da família, indicamos a validade do conceito de gênero como marcador de assimetrias/desigualdades que ainda se apoiam na binaridade hierárquica de pares como masculino/feminino, homem/mulher. Neste sentido, podemos afirmar que com o conceito de gênero podemos mobilizar um debate político necessário e atual sobre como diferenças sexuais se materializam em corpos biológicos, porque o processo de discussão da heteronormatividade passa pela crítica às identidades de gênero e suas consequências nas relações sociais. Tudo isso indicaria a necessidade de pensar como, em determinados contextos, a mobilização do conceito de gênero ainda pode ser estratégica no enfrentamento das discriminações sexuais e sociais no que diz respeito às mulheres e ao enfrentamento das diferentes formas de violência - física e simbólica - que ainda nos desafiam.

O debate sobre gênero e educação tem na pesquisa da educadora Guacira Lopes Louro (1987; 1997; 2010) importante contribuição, na medida em que seus trabalhos apontaram a necessidade de pensar as diferentes marcações da hierarquia sexual no ambiente escolar a partir de uma perspectiva pósestruturalista coerente com a nossa abordagem nesse artigo. No campo do ativismo, o Plano Nacional de Políticas para as Mulheres 2013-2015 foi decisivo. No capítulo sobre educação, reconhece a escola aqui tomada no seu sentido mais amplo - como um lugar que "acaba reproduzindo a desigualdade vivida entre as pessoas na sociedade, seja nos currículos, nos livros didáticos, nas práticas das salas de aula ou nos procedimentos de avaliação" (PNPM, p. 23). Embora haja inúmeras iniciativas de construção de espaços de debate sobre a desigualdade de gênero na sociedade, este artigo parte do princípio de que cabe a todas as esferas da educação promover o debate sobre igualdade de gênero, de modo a produzir um necessário, urgente e obrigatório debate sobre igualdade de gênero. Entendemos ainda que tão importante quanto falar sobre a igualdade de gênero, é promovê-la a partir de uma política de educação que permita questionar a hegemonia do saber como privilégio masculino, introduzindo então não apenas o conceito de gênero, com o qual se pode desnaturalizar formas de opressão, mas sobretudo desenvolvendo a possibilidade de construção de uma epistemologia feminista, que contemple, em todas as áreas de saber, a leitura de autoras mulheres. Nesse duplo movimento - educar para que os papéis de gênero possam ser desnaturalizados e formar alunos e alunas a partir da perspectiva de pensamento de mulheres, não apenas sobre mulheres -, se poderia obter também um duplo resultado, qual seja, o de construir, a partir da escola, horizontes simbólicos para as mulheres e roteiros de vida nos quais a 
subalternidade não seja destino necessário. Se tudo isso já era importante quando o Plano Nacional de Políticas Públicas para as Mulheres foi votado, tornou-se tarefa ainda mais urgente em um contexto em que as poucas conquistas alcançadas estão sob forte ameaça de retrocesso onde houve ainda tão pouco avanço.

\section{Referências}

ARAGÃO, L. T. Em nome da mãe. In: Perspectivas Antropológicas da Mulher, 3. Rio de Janeiro: Zahar, 1983.

BEAUVOIR, S. O segundo sexo. Rio de Janeiro: Nova Fronteira, 2009.

BONTE, P. F. Héritier - pour une anthropologie symbolique du corps. In: MEMMI, D. La tentations du corps. Paris: Édititons de l’École des Hautes Études en Sciences Sociales, 2009.

BUTLER, J. "Variações sobre sexo e gênero: Beauvoir, Wittig e Foucault”. In: BENHABIB, S.;

CORNELL, D. Feminismo como crítica da modernidade. Rio de Janeiro: Editora Rosa dos Tempos, 1987.

, J. "Fundamentos contingentes: o feminismo e a questão do pós-modernismo". Cadernos

Pagu, n. 11. 1998.

J. “Corpos que pesam: sobre os limites discursivos do 'sexo”. IN: LOURO, G. O corpo educado: pedagogias da sexualidade. Belo Horizonte: Autêntica, 2001.

, J. Problemas de gênero: feminismo e subversão da identidade. Tradução de Renato Aguiar. Rio de Janeiro: Civilização Brasileira, 2003.

J. Undoing gender. New York \& London: Routledge, 2004.

CABRAL, C. S.; HEILBORN, M. L. "Pesquisa qualitativa sobre aborto: aportes sociológicos para a saúde pública”. In: ARILHA, M; LAGO, T. (Org.). Cairo + 20 e Políticas Públicas no Brasil: consolidando e ampliando direitos. São Paulo: Oficina Editorial, 2014. pp. 55-86.

CAILLE, A. Nem holismo nem individualismo metodológicos: Marcel Mauss e o paradigma da dádiva. RBCS 13(38), 1998

COLLIER, J.; YANAGISAKO, S. Gender and Kinship. Essays toward a unified analysis. Stanford: Stanford University Press, 1987

CORNELL, D. “Gender, sex, and Equivalent Rights”. In: BUTLER, J; SCOTT, J. (Orgs.). Feminists theorize the political. Routledge: New York \& London, 1992.

D. Beyond Accommodation - ethical feminism, deconstruction and the law. Boston:

Rowman\&LittlefieldPublishers, 1999.

DUARTE, L. F. D. Da vida nervosa nas classes trabalhadoras urbanas. Rio de Janeiro: CNPq; Jorge Zahar, 1986. 
DURKHEIM, E; MAUSS, M. "De ciertas formas primitivas de clasificación. Contribuición al estudio de las representaciones colectivas". (1903) IN: MAUSS, M. Institución y Culto. Representaciones colectivas y diversidad de civilizaciones. Barcelona: Barral Editores, 1971.

FONSECA, C. Cavalo amarrado também pasta: honra e humor em um grupo popular brasileiro. Revista Brasileira de Ciências Sociais [Anpocs], v. 6, n. 15, pp. 27-39, fev. 1991.

FOUCAULT, M. A microfísica do poder. Tradução Roberto Machado. Rio de Janeiro: Graal, 1982. , M. História da sexualidade, volumes I, II, III. Rio de Janeiro: Graal, 1988. , M. As Palavras e as Coisas. Uma arqueologia das ciências humanas. São Paulo: Martins Fontes, 2000.

FRANCHETTO, B; CAVALCANTI, M. L. V. C.; HEILBORN, M. L. “Antropologia e Feminismo”. In: Perspectivas antropologicas da mulher. Rio de Janeiro: Zahar Editores, 1981.

GILLIGAN, C. “Women’s Place in Man's Life Cycle.” Harvard Educational Review, 29. 1979

Gilligan, C. In A Different Voice. Cambridge, Mass.: Harvard University Press, 1982.

HARRIS, O.; YOUNG, K. (Orgs.). Antropologia y Feminismo. Barcelona: Anagrama 1979.

HEILBORN, M. L. e SORJ, B. "Estudos de gênero no Brasil”. In: MICELI, S. (Org.) O que ler na ciência social brasileira (1970-1995), ANPOCS/CAPES. São Paulo: Editora Sumaré, 1999, pp. 183-221.

HÉRITIER, F. Masculin/ féminin. La pensée de la difference. Paris: Odyle Jacob, 1996

HIRATA, H. Entrevista. Trabalho, Educação e Saúde. Rio de Janeiro, v. 4, n. 1, 2006. pp. 199-203. , H.; GUIMARÃES, N. A. (Orgs.). Cuidado e cuidadoras. As várias faces do trabalho do care. 1. ed. São Paulo: ATLAS, 2012. p. 248.

LAQUEUR, T. W. Inventando o sexo: corpo e gênero dos gregos a Freud. Rio de Janeiro, Relume Dumara, 2001.

LOURO, Guacira Lopes. Prendas e Antiprendas. Uma escola de Mulheres. Porto Alegre : Editora da Universidade Federal do Rio Grande do Sul, 1987. . Gênero, sexualidade e educação. Uma perspectiva pós-estruturalista. Petrópolis, RJ : Editora Vozes, 1997.

. O corpo educado. Pedagogias da Sexualidade. Belo Horizonte : Autêntica Editora, 2010.

MAUSS, M. "Ensaio sobre a Dádiva: forma e razão da troca nas sociedades arcaicas. In: Sociologia e Antropologia. São Paulo: Cosac \& Naify, 2003.

MOORE, H. A passion for difference. Indiana University Press, 1994

ORTNER, S. e WHITEHEAD, H. (eds). Sexual Meanings: The Cultural Construction of Gender and Sexuality. Cambridge, Cambridge University Press, 1981.

OUSDHOORN, N. Beyond the Natural Body. An Archeology of Sex Hormones. London and New York: Routledge, 1994.

PIERUCCI, A. F. As ciladas da diferença. São Paulo: Editora 34, 1999. 
Plano Nacional de Políticas para as Mulheres. Brasilia: Secretaria de Políticas para as Mulheres, 2013. <http://www.spm.gov.br/pnpm/publicacoes/pnpm-2013-2015-em-22ago13.pdf>

REITER, R. (ed). Toward an Anthropology of Women. New York, Monthly Review Press, 1975.

RODRIGUES, C. "Diferença sexual, direitos e identidade: um debate a partir do pensamento da desconstrução”. Cadernos Pagu. 2010, n. 34, pp. 209-233.

C. Antígona: lei no singular, lei do singular. Belo Horizonte: SapereAude, v. 3 - n. 5, pp. 32-54,

2012b,

C; HEILBORN, M.L. "Gênero e Pós-gênero: um debate político”. In: Anais eletrônicos do Seminário Internacional Fazendo Gênero 10. Florianópolis, 2013.

ROSE, N. Governing the soul. The shaping of the private self. London: Routledge,1989.

RUBIN, G. "The traffic in women: notes on the 'political economy of sex"'. In: REITER, R. (ed):

Toward an Anthropology of Women. New York, Monthly Review Press, 1975, pp. 157-211.

, G. “Thinking Sex: Notes for an Radical Theory of the Politics of Sexuality”. In: VANCE,

C. (ed.). Pleasure and Danger. Exploring Female Sexuality. Boston: Routledge and Kegan Paul, 1984. pp. 267-319.

SARTI, Cynthia A. "Reciprocidade e hierarquia: relações de gênero na periferia de São Paulo". Cadernos de Pesquisa. São Paulo, n. 70, pp. 38-46, ago. 1989.

SCHULTZ, V. "Women 'before' the Law”. In: BUTLER, J.; SCOT'T, J. (Orgs.). Feminists theorize the political. Routledge: Nova York \& Londres, 1992.

SCOTT, J. "Gênero: uma categoria útil de análise histórica”. In: Revista de educação e Realidade n. 2;v. 15. Porto Alegre (5-22), 1990.

J. “Entrevista com Miriam Grossi e Maria Luiza Heilborn”. Revista de Estudos Feministas. v. 6, n. 1, 1998.

SHAPIRO, J. "Anthropology and the study of gender". In: Soundings, an interdisciplinary journal. 64, n. 4: 446-65, 1981.

SORJ, B. "Sociologia e trabalho: mutações encontros e desencontros". Revista Brasileira de Ciências

Sociais, São Paulo, v. 45, n. 43, jun. 2000. pp. 25-34.

TRONTO, J. C. “Care as a political concept”. In: HIRSCHMANN, N. J.; DI STEFANO, C. (Org.).

Revisioning the political: feminist reconstructions of traditional concepts in Western political theory. Boulder: Westview Press, 1996. pp. 139-156. 